ciency of conjunctiva, but not so with the corneal, so the suture was passed through a portion of the sclerotic at its corneal junction, which closed the wound satisfactorily. The after-treatment consisted in the application of ice to the eye, atropine and leeches. In filty hours the lateral sutures were removed, when the wound was found to be well adhered. On tho next day, effort was made to remove the central suture, but as the wound showed signs of gaping if much interfered with, it was not removed until the following day, when the wound was found to be well united.

There was a little conjunctival injection, which disappeared in a fow days. Patient sees as well, or nearly so, as with the other eye, which is normal.

Eye and Ear Department, Northern $\}$ Dispensary, New York City. $\}$

\title{
SINGULAR TUMOR IN A COW'S BLADDER.
}

[Communicated for the Boston Medlcal and Surgical Journal.]

A NEIGHBOR of mine relates the following remarkable freak of nature in one of the lower animals. One of his cows, he noticed, had been gradually losing her milk, and wasting away in flesh and strength for six or eight weoks. Her main difficulty seemed to be inability to urinate. She would place herself in position to accomplish that object, but only a drizzling of urine would come away, after long-continued straining. At length she becamo too weak to rise, and to end her misery he killed her. Anxious to know more of the cause of her suffering and emaciation, he examined the body after death, but found no important organ of the system diseased till he came to the bladder, which was greatly distended with urine. On opening it, he discovered a tumor, of nearly the size of the double fist, firmly attached to the walls of the bladder upon one side, covering an attaching space of nearly two inches in diameter, near the orifice of the urethra. That portion of the tumor facing inwards upon the bladder had the appearance of a full-blown rose in color and shape, and one of the petals, more pendulous than the rest, was turned partly over the urinary passage, shutting down upon it, probably, in each attempt to urinate, thus giving rise to the drizzling of the urine and to its almost complete retention. This surface was also nodulated, and somo portions of it had the appearance of commencing suppuration. Upon cutting into the tumor, it was found to be hard and tough. The appearance of the urine was not particularly noticed.

Was this a cancerous growth? We read of polypous, fungous, steatomatous, erectile and other morbid growths in the human bladder. Occasionally, we find scirrhus and cancer in that organ. Which of these was it? Why may not the same diseases, in a more aggra- 
vated form if possible-the same tumors, much larger in their dimensions-affect also the similar organ in the lower animals? In both, they are equally incurable. Death, sooner or later, will be the result.

Esscx, Vt., October, 1865. .

L. C. Bu'sler.

\section{Feports of Atedical Sorieties.}

EXTRAOTS FROM THE RECORDS OF THE BOSTON SOCIETY FOR MEDICAL IMPROVEMENT. BY FRANCIS MINOT, M.D., SECRETARY.

Aug. 14th.-Horse-raitroad Accident; Amputation of the Thigh just above the Knee, in a Boy at. 13; Tetanus ; Death ; Osteo-myelitis ; Necrosis.-Specimen showed and case reported by Dr. HoDges.

The injury affected in no appreciable manuer either the soft parts or the bone above the tibia. The amputation (circular) was performed, under ether, at the Massachusetts General Hospital, July 23d, 1865, one hour after the accident, and the patient's condition both before, during, and subsequent to the operation, was as good as could be. The only noticeable incident in its performance was a hæmorrhage from the medulla, profuse, considering the source, and not easily controlled. It was finally arrested, after various means had failed, by a pledget of lint, held in place by a sponge and bandage. The central portion of the stump was consequently left open, though the sutures necossary to bring the flaps together wore passed; this was done twelve hours afterwards, tho sponge and lint being removed by ligatures attached to them at the time of their application. In all these manipulations the medulla was treated in the gentlest manner, and no styptics were used. Until the 26th there was a little delirium. Aug. 1st, all the ligatures had come away. The union having failed in the central part of the stump, the gaping edges were at this point separated by a globular, fungous growth, protruding from the medullary cavity of the bone, dark-red, firm in texture and smooth of surface, the size of a large crab-apple. By the aid of a director, this was broken off at its pedicle, which was tough, and continuous with tho medulla. No hæmorrhage followed. The stump was otherwise in excellent condition, and the patient himself was so well as to be removed from a private room to the general ward. A microscopic examination of the removed mass showed it to be composed of a granular stroma, with some fino fibres, oil globules, and red and white bloodcorpuscles, the latter in large numbers.

Aug. 5th, without any special assignable cause, trismus and stiff neck appeared, which, by the 7 th, became a general tetanus, continuing until the 10th, when the patient died. Subcutaneous injections of morphine were the essential treatment of the disease, and afforded the greatest relief. The appetite, throughout the sickness, was pretty good, and broth, eggs, bread and milk, soft pudding, and milk-punch were freely taken. A generous diet had been allowed from tho time of the operation. The pulse ranged from 120 to 136 ; the pupils were moderately dilated; the skin was moist and the urine natural up to 